\title{
Factors Affecting Nurses Compliance Regarding the Care of Patients with Chest Trauma
}

\author{
Mohammed M. AL-Gabri ${ }^{1}$, Mona A Mohammed ${ }^{2}$, Mogedda M. Mehany ${ }^{3}$. \\ 1. Assistant Lecture of Critical Care Nursing, Faculty of Medicine and Health Sciences, Thamar University. \\ 2. Assistant Professor of Critical Care Nursing Department, Faculty of Nursing, Assiut University, Egypt. \\ 3. Assistant Professor of Critical Care Nursing Department, Faculty of Nursing, Assiut University, Egypt.
}

\begin{abstract}
Background: Chest trauma remains to show a high incidence in the emergency room among trauma patients. The Nurse is involved with the care of the trauma patient from arrival in the emergency department to follow-up in the trauma clinic. The aim of this study was to assess Factors Affecting Nurses Compliance Regarding the Care of Patients with Chest Trauma. Design: a Descriptive Study. Setting: This study was carried out in the emergency trauma unit at Assuit University Hospital. A sample: of this study were all available nurses working in the emergency trauma unit at an Assuit University Hospital (40). (Tools): two tools used in this study Tool I: nurses selfadminister question part: I demography data part: II Factors Affecting Compliance Tool II: Nurses Compliance Assessment sheet. Results: all of the studied stated that didn't have with (clear job description, oriented or continuous training courses, also no written information such as (poster, brochure). not have library equipped new books, Journal websites to update their knowledge and practical skill regarding the care of patients with chest trauma. not receiving any Undergraduates courses and no financial resources in the chest trauma unit. Conclusion: all of the nurses did not have clear job descriptions, oriented or continuous training courses. Recommendations: Provide the nurse with a clear job description Update their knowledge and practical skill nurses about chest trauma, Undergraduates courses about chest trauma continue, and financial advantages in the trauma unit.
\end{abstract}

\section{Keywords: Factors affecting, Compliance, Chest Trauma \& Trauma Emergency Unit.}

\section{Introduction}

Chest trauma, the relatively sudden application of large physical forces to the chest, is a frequent cause of serious and fatal injury in present-day society. It has been estimated that $25 \%$ of chest trauma fatalities due to motor vehicle accidents. (Crayen, 2011). Chest injury can be either closed (blunt) or open (penetrating) injury and is further classified into primary injury and secondary injury. This classification is rather more useful while considering therapeutic and preventive strategies (Chowdhury et al., 2014).

Trauma nurses are involved with the care of the patients with chest trauma from arrival in the emergency department to follow-up in the trauma clinic. They respond to all Class 1 and Class 2 trauma activations and facilitate the patients care process from the trauma bay to diagnostic imaging and on to the intensive care unit. They perform procedures including chest tube insertion, central line insertion, arterial line insertion, and laceration repair, and act as a first assistant during trauma surgeries (Stewart, 2014).

Compliance is the extent to which certain behavior (for example, following physician's orders or implementing healthier lifestyles) in accordance with the physicians' instructions or health care advice. Compliance can be influenced or controlled by a variety of factors like culture, economic and social factors, self-efficacy, and lack of knowledge or means. Guidelines that guide an individual's behavior exist in a variety of settings (including health care settings). (Efstathiou, Papastavrou, Raftopoulos, \& Merkouris, 2011)

Compliance with chest trauma was considered if standard precautions were taken by all team members. Team present was considered when the entire team called was present at the ED before the arrival of the patient. Secondary outcome measures were overall trauma resuscitation time (TRT), the timing of ATLS steps (ABCDE) and mortality. The TRT was defined as the time span from entering the trauma room until completion of the "primary survey" and the "secondary survey" including radiology, or by indicated early departure or death. Mortality was defined as death resulting from trauma within 30 days after admission. (Spanjersberg, Bergs, Mushkudiani, Klimek, \& Schipper, 2009)

Significant

Attended patient cases at Trauma Unit in the assuit University Hospitals were 19,869 in 2002 and increased up to 32,699 in 2009.from Out of the total cases in 8 years of study duration and According to the annual record of Assuit Hospital University 1032 of patients were admitted to the emergency trauma department during the year of 2016. The number of 
cases frequent in the trauma unit of the year during 2019. 42350 cases As for the number of admission cases to the injury unit 14483 Number of deaths during the same year 360 injured and Number of deaths during the first 24 hours 63 deaths And the numbers of the beds in the department are thousand forty beds Approximation (Record of trauma emergency unit Assuit hospital2019).

Aims of the study

The aim of this study was to assess Factors Affecting Nurses Compliance Regarding the Care of Patients with Chest Trauma.

\section{Research questions:}

The study was directed to answer the following research questions.

What is Trauma Emergency Nurse's Compliance regarding the care of patients with Chest Trauma? What are the factors affecting nurses compliance?

\section{Subjects \& Methods \\ Study design \\ The design of this study was a Descriptive design. \\ Study Settings}

This study was conducted in the emergency trauma unit at Assuit University Hospital.

\section{Sample size}

All available nurses working in the emergency trauma unit at assuit university hospital (40) were having more than one-year clinical experience and providing direct care to the trauma patients.

\section{Study tools:}

Tools were utilized to collect data in this study includes:-

\section{Tool I: Nurses Self Administer Questioner \\ Part I: (demographic Data)}

It included items related to nurses' personal data of studied nurses such as Code, age, sex, marital status, current occupation, the degree of qualification, years of experience in caring of chest trauma, attendance of related training courses, date and time of courses.

\section{Part I I: factors affecting}

This tool was developed by the researcher related to identifying factors affecting compliance emergency trauma nurses regarding the care patients with chest trauma containing $\mathbf{1 7}$ items, questions a group of (yeas) or (no) which included 17 items classified as the following; percentage Distribution of nursing Compliance regarding the care patients with chest trauma (8 items), and Table continue percentage Distribution of nursing Compliance regarding chest trauma (9 items).

\section{Tool tow (Nurses Compliance Assessment Sheet)}

It included 6 items containing 52 questions, divided into two groups of questions a group of M.C.Q statements which included 44 questions classified as the following; anatomy \& physiology of respiratory system (21 questions), Information about definition of chest trauma (4 questions), mechanism and classification of chest trauma (5 questions) and causes and diagnosis of chest trauma (10 questions), management and life-threatening situation of chest trauma. (12 questions) and a group of open Questions statements which included (8 questions) regarding the nursing team Duties in patients with chest trauma. Nurses' responses were about what he knows about chest trauma calculated as the right answer took one score and the wrong answer took zero.

\section{Preparatory phase}

- Official permission from the dean of the faculty of nursing to conduct the study was delivered to the hospital authorities in the Assiut university hospital and approval to conduct this study was obtained.

- Two tools were utilized for data collection in this study, "Nurses Self Administer Questions)" (tool one), ((Nurses-Compliance Assessment Sheet)). (Tool two), that tool was developed by the researcher to identify factors affect for noncompliance with chest trauma care among emergency trauma nurses.

- Content validity of the developer tools was done by 5 experts in the related fields. Three assistant professors of critical care nursing from Faculty of Nursing Assiut University. Two professors of critical care medicine from Assiut Faculty of Medicine.

- A pilot study carried out before starting of data collection to test the feasibility and the clarity of the study tools on $10 \%$ of the sample, the analysis of pilot study define the modification required in the tool used, and the necessary modifications was done prior to data collection.

- The overall reliability of the tools were tested using $(\alpha)$ Cronbach's test for the pilot study results. It was found that the reliability of the tool one equal to 0.80 and the tool tow equal to 0.84, which was acceptable. 


\section{Ethical considerations}

- The research proposal was approved from the Ethical Committee in the faculty of nursing.

- There is no risk for nurses during the application of research.

- The study was followed by common ethical principles in clinical research.

- Written consent was obtained from nurses that are participated in the study, after explaining the nature and purpose of the study.

- Confidentiality and anonymity were assured.

- Nurses had the right to refuse to participate and or withdraw from the study without any rational any time.

- Nurse's privacy was considered during the collection of data.

Implementation phase

- Data was collected at an emergency trauma unit at Assuit University Hospital

- Data were collected during the period from August 2017 to February 2018.

- The purpose of the study was to assess Factors Affecting Nurses Compliance Regarding the Care of Patients with Chest Trauma.

- Permission for conducting the study was taken from the head of the nurse responsible for training after explaining the purpose, the time and the place of the study. Then she informed the head nurses of the emergency trauma unit to obtain cooperation.

- Nurses were informed to participate in the study according to their need. Some nurses refused to participate throughout the study phases were not mandatory. Agreement on participation in the study was taken orally from nurses.

- Many copies of the questionnaire (Tool I), and questionnaire (Tool II) were prepared by the researcher

- Interview questionnaire sheet: after taking the nursing oral agreement for voluntary participation in the study, each nursing was communicated personally by the researcher to fulfill the nursing assessment sheet.

- Filled after the purpose of the study was explained to the nurse prior to answering the question using (tool one and two)

\section{Evaluating Phase}

Each trauma nurse evaluated once by using (Nurses Self Administer Questions)" (tool one), ((NursesCompliance Assessment Sheet)). 


\section{Results}

Table (1): Frequency of Percentage Distribution of the studied nurses is according to demographic characteristics $(\mathrm{No}=\mathbf{4 0})$.

\begin{tabular}{|c|c|c|}
\hline Items & No & $\%$ \\
\hline \multicolumn{3}{|l|}{ Age: } \\
\hline$<20$ & 2 & 5.0 \\
\hline $20->25$ & $\overline{17}$ & $\overline{42.5}$ \\
\hline $25->30$ & $\overline{19}$ & $\overline{47.5}$ \\
\hline$\geq 30$ & 2 & $\overline{5.0}$ \\
\hline 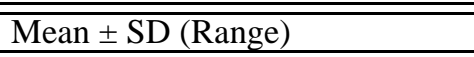 & \multicolumn{2}{|l|}{$\overline{24.9+3.6(19-35)}$} \\
\hline \multicolumn{3}{|l|}{ Gender: } \\
\hline Male & 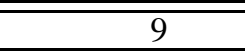 & 22.5 \\
\hline Female & 31 & 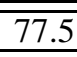 \\
\hline \multicolumn{3}{|l|}{ Marital status } \\
\hline Single & 29 & $\overline{772.5}$ \\
\hline Married & 11 & 27.5 \\
\hline \multicolumn{3}{|l|}{ educational level } \\
\hline - $\quad$ Nursing Diploma & 13 & 32.5 \\
\hline - Technical Institute of Nursing & 27 & 67.5 \\
\hline - B.Sc. Nurses & $\overline{0}$ & $\overline{\overline{000}}$ \\
\hline \multicolumn{3}{|c|}{ Years of experience at the emergency department } \\
\hline$-\overline{-<5}$ & $\overline{17}$ & $\overline{42.5}$ \\
\hline $5-<10$ & $\overline{13}$ & 32.5 \\
\hline$\geq 10$ & 10 & 25.0 \\
\hline Mean \pm SD(range) & $5.5+3.5(1-12)$ & \\
\hline \multicolumn{3}{|c|}{ - attendance of previous training chest trauma } \\
\hline Attended & 1 & 2.5 \\
\hline Not attended & 39 & $\overline{997.5}$ \\
\hline
\end{tabular}

Table (2): Frequency Percentage Distribution of the studied nurses regarding factors affecting Compliance regarding the care patients with chest trauma.

\begin{tabular}{|c|c|c|c|c|}
\hline \multirow{2}{*}{ Items } & \multicolumn{2}{|c|}{ Yes } & \multicolumn{2}{|c|}{ No } \\
\hline & No & $\%$ & No & $\%$ \\
\hline - Availability of clear job description for nursing staff in trauma unit. & 0 & 0 & 40 & 100 \\
\hline - Is there a direct supervisor and guidance from the head nurse? & 35 & 87.5 & 5 & 12.5 \\
\hline $\begin{array}{l}\text { - Attendance of oriented program about chest trauma before working } \\
\text { trauma unit. }\end{array}$ & 0 & 0 & 40 & 100 \\
\hline - Availability continuous training courses for chest trauma. & 0 & 0 & 40 & 100 \\
\hline $\begin{array}{l}\text { - The policy of unit gives independence role in caring for the patient } \\
\text { with chest trauma. }\end{array}$ & 4 & 10 & 36 & 90.0 \\
\hline $\begin{array}{l}\text { - Availability written information such as poster, brochure in trauma } \\
\text { unit department. }\end{array}$ & 0 & 0 & 40 & 100 \\
\hline - Availability libraries equipped, new book, Journal website. & 0 & 0 & 40 & 100 \\
\hline $\begin{array}{l}\text { - Do you have time to update your knowledge and practical skill in } \\
\text { chest trauma through the website, Journal or libraries? }\end{array}$ & 0 & 0 & 40 & 100 \\
\hline
\end{tabular}


Table (3): (Cont.) Frequency Percentage Distribution of the studied nurses regarding factors affecting Compliance regarding the care patients with chest trauma.

\begin{tabular}{|c|c|c|c|c|}
\hline \multirow{2}{*}{ Items } & \multicolumn{2}{|c|}{ Yes } & \multicolumn{2}{|c|}{ No } \\
\hline & No & $\%$ & No & $\%$ \\
\hline $\begin{array}{l}\text { - Increase number of working hours in the trauma unit department } \\
\text { through morning, afternoon, night shift. }\end{array}$ & 9 & 22.5 & 31 & 77.5 \\
\hline $\begin{array}{l}\text { - Nursing staff have good chance to provide nursing care in the } \\
\text { trauma unit. }\end{array}$ & 36 & 90.0 & 4 & 10.0 \\
\hline $\begin{array}{l}\text { - Nursing staff and resources available in the unit compared to the } \\
\text { number of the patient entering the trauma unit. }\end{array}$ & 7 & 17.5 & 33 & 82.5 \\
\hline $\begin{array}{l}\text { - Assigning any additional administrative work other than nursing } \\
\text { care. }\end{array}$ & 5 & 12.5 & 35 & 87.5 \\
\hline - Undergraduates courses does not cover chest trauma. & 0 & 0 & 40 & 100 \\
\hline $\begin{array}{l}\text { - Communication with the rest of the department after providing } \\
\text { primary care in the injuries unit. }\end{array}$ & 23 & 75.5 & 17 & 42.5 \\
\hline $\begin{array}{l}\text { - There are no time and material to achieved obligation universal } \\
\text { precautions. }\end{array}$ & 28 & 70.0 & 12 & 30.0 \\
\hline - Lack of financial advantages in trauma unit. & 0 & 0 & 40 & 100 \\
\hline $\begin{array}{l}\text { - Cooperation between colleagues from nursing staff and other } \\
\text { administrative staff and supervisors. }\end{array}$ & 10 & 25.0 & 30 & 75.0 \\
\hline
\end{tabular}

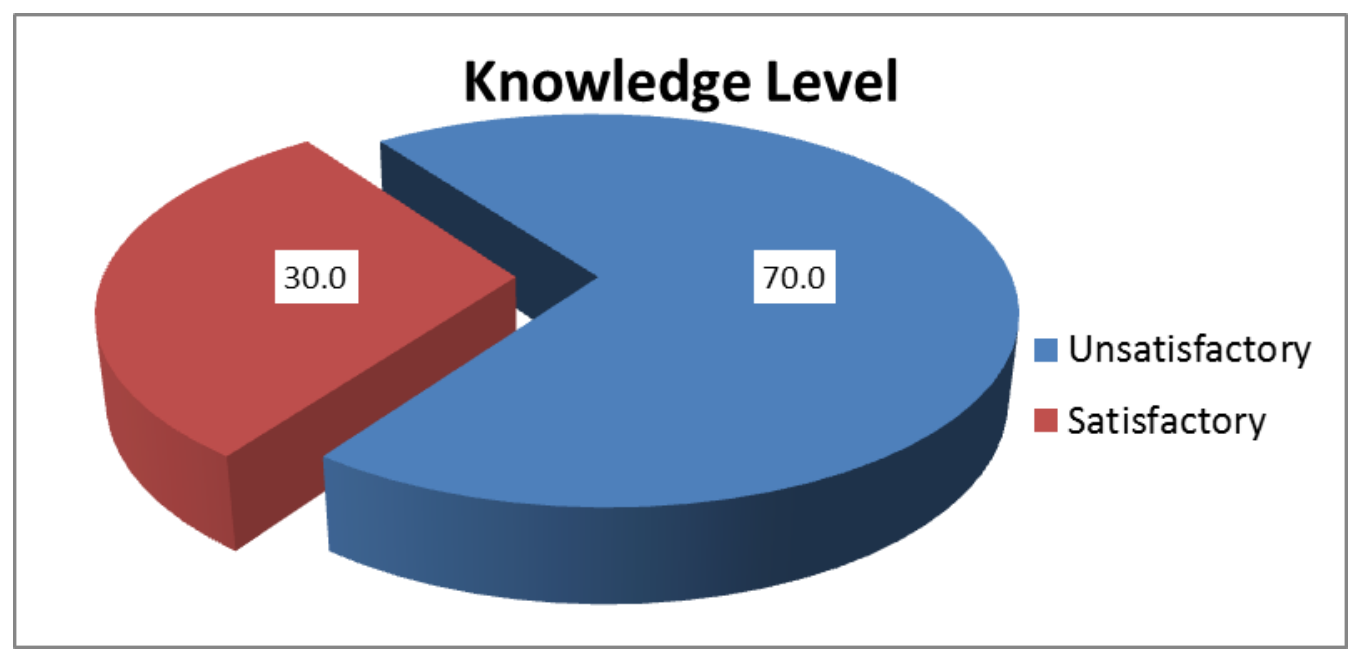

Figure (1): Level of satisfaction among Nurses' total scores of Nurses Knowledge chest trauma Compliance Assessment Sheet $(\mathrm{No}=40)$.

Table (1): Shows the demographic data of studied nurses. It was found that $47.5 \%$ of them were in the age group from 25 to 30 years, $77.5 \%$ were females and $72.5 \%$ were single concerning their educational level $67.5 \%$ of the technical institute of nursing, $32.5 \%$ of the nurses held a nursing diploma. Moreover, $42.5 \%$ nurses had work experience in nursing less than 5 years. $32.5 \%$ of them had from 510 years'. In relation to their previous training on course chest trauma, the table reveals that $97.5 \%$ of them were not receiving any previous course about chest trauma training.

Table (2): This table cleared that, Regarding to Frequency Percentage Distribution of the studied nurses regarding factors affecting Compliance regarding the care patients with chest trauma.the findings revealed that all the nurses have not clear job description for nursing staff in trauma unit, not have any orientation or continuous training courses for chest trauma, not have any availability written 
information such as poster, brochure, journal and libraries equipped, new book, Journal website in trauma unit department, did not have any update their knowledge and practical skill in chest trauma through the website, journal or libraries respectively.

Table (3 Cont): This table cleared that, regarding to Frequency Percentage Distribution of the studied nurses regarding factors affecting Compliance regarding the care patients with chest trauma. The findings revealed that all the nurses were not receiving any undergraduates courses covered chest trauma, reporting lack of financial advantages in trauma unit and of them $90 \%$ had good chance to provide nursing care respectively)

Figure (1): This figure shows that the majority of the nurses $(70 \%)$ had unsatisfactory. Level of nurses Knowledge chest trauma Compliance Assessment regards total score, while $(30 \%)$ satisfactory Level total scores about chest trauma Compliance Assessment.

\section{Discussion}

Thoracic trauma is one of the major heavy loads in poly-traumatized patients. Traumatic injury is even the most common cause of death. Thoracic injuries are responsible for twenty five percent of deaths Milisavljević et al., (2016) currently, injury in India is a big cause of years of productive life lost and the leading cause of death for those under Thirty-five years old. This national injury heavy loads is growing and the ongoing rise in the trauma burden is mostly in the form of road traffic crashes(Mitra et al., $2017 \&$ Chowdhry \& Rathinam, 2017).

The current study was aimed to assess factors affecting Trauma Emergency Nurse's Compliance regarding the care of patients with Chest Trauma.

The results of the present study showed that more than half of the nurses were in the age group from twenty-five to thirty years, Females, and Single, more than half of the nurses were in the qualification of Technical Institute of Nursing This study may be due to the old belief that nursing is profession to females so most of the nurses in Egypt are females. This result is in agreement with Diab \& Mabrouk, (2015) Who reported that most of the nurses their age ranged from twenty-five to Twenty-nine years, and working as staff nurses at specialty hospital setting, as regards the educational level; Most of the nurses had diploma of nursing, their experiences below five years, and difficult chance to attend training courses about the disasters, and obtained information on disasters through different mass media. Also, this finding is in accordance with Ibrahim, (2016). Who stated that slightly more than half of them were aged less than thirteen years. More than half of the studied nurses had a technical education. And half of them their years of experience at the emergency department low fifth. also this in agreement with a study done by Elfaki et al., (2016) Who mentioned that, about half of them had less than ten years' experience And the agreement with a study done by Ibrahim,b (2016) According to their years of experience it was found that less than two-thirds of them had experienced less than five years. The present study disagreed with a study done by Elfaki et al., (2006). The study was included fifty nurses, their age range from 21-45years.

The present study the findings revealed that really all nurses had not attended any previous training courses about chest trauma. This went in the line with Bedier et al., (2016) who reported in their study indicated that the majority of studied nurses did not have any undergraduate training courses about chest trauma care as they graduated from secondary nursing school and about half of them had less than ten years' experience. Also, they did not attend any postgraduate training program related to chest trauma. Also,this is in agreement with Ibrahim, (2016) majority of nurses had not attended educational lectures or workshops concerning chest trauma management.

The findings revealed that all nurses that majority of them were not receiving any previous course chest trauma training. The findings of the present study indicated that the majority of studied nurses did not have any undergraduate training courses about chest tube care as they graduated from secondary nursing school and about half of them had less than 10 years' experience. Also, they did not attend any postgraduate training program related to chest trauma or chest tube. While only one-third of them attended a training program related to infection control (Bedier et al., 2016).

As revealed from the current study, the majority of the nurses did not have (clear job description, oriented or continuous training courses, also no written information such as (poster, brochure).nursing staff did not have library equipped new book, journal website to update their knowledge and practical skill in chest trauma. not receiving any undergraduates courses and no financial advantages in trauma unit chest trauma this is may be attributed to no specialty in the nursing staff and not clear job description, oriented ,continuous program need financial cost and trauma unit not have additional financial cost to cover these program and library, also overcrowding and increase workload in trauma unit increase due to flow of emergency patients in this type of unit prevent them in updating their knowledge, lack of education courses related to the care of the patient with chest trauma. in a diploma degree and technical institute of nursing, another factor for lack of nurses' practice in 
the current study was nurses' workload which made the delay of nurses' abilities and motives to acquire and update their practice.

This study finding is in agreement by Chipeta et al., (2016) who mentioned that clear job description improved nurses job satisfaction and staff retention which are crucial to the provision of high-quality care and will also ensure efficiency in health care delivery in Malawi. Moreover, Tevington, (2011). Who stated that The American Nurses Association advocates legislation that will empower nurses to create valid, reliable unit and patient-specific staffing plans, and require public reporting as outlined in The Registered Nurse Safe Staffing. Similarly, This study finding is in agreement with Hertel, (2011) Who stated that The debate over nurse-patient staffing ratios is complex and introducing politicians into the mix increases the complexity Nursing staffing ratios to patient have recently taken on renewed importance due to patients being better informed, higher acuity levels, budgetary concerns which are resulting in cutbacks at every level of health care, and the aging of the nursing workforce. This study result is in agreement with José, etal., (2013)who mentioned that the professionals are faced with elevated workloads, inadequate physical spaces, and with insufficient material resources and equipment, which along with compromising the quality of care delivered, causes suffering, dissatisfaction and conflict.

This study finding is in agreement with Ibrahim, (2016) \& (Hassanin \& Mohammed, (2016) who stated that whatever with knowledge and practice learned in nursing school they were tended to be forgotten if not applied or stressed on. also, lack of continuing education programs, in-service training and proper supervision, may also contribute to the problem. Moreover, this is in agreement with Chichom-Mefire, et al., (2015) who reported that lack of specific trauma-related training is a general rule in most low-income countries. The contribution of specific training of staff involved in the management of injury cases appropriate to their outcome is well established.

This study findind is in agreement with Fashafsheh \& Morsy, (2013). Who stated that nurses were the workload that did not give them time to attend continuous educational workshops or lectures. On the other hand, there are no policies in the $\mathrm{MOH}$ (Malawi's Ministry of Health) that encourage nurses' continuous education like free educational hours or even days and lack of internet access facilities in the department or setting rooms that can facilitate and encourage nurses for the update to refresh their knowledge. These results agree with Cattermole, et al., (2018) who mentioned that textbooks are expensive to produce, distribute and purchase; they are also rapidly superseded by the latest developments in healthcare. Journals are more current but no single journal is comprehensive for emergency medicine practice, and the volume of publications prohibits any one person from being able to keep on top of all of them. Although more up to date in delivery, conferences are expensive to attend.

As revealed from the current study, that most of the nurses did not assigned (any administrative work other the nursing care, no available resources in the unit, not received any undergraduates courses and no financial advantages in trauma unit this may be attributed to lack of incentives, lack of confidence, clinician cynicism, poor communication, poor preparation for leadership roles, curriculum deficiencies at undergraduate level and health professional courses, inadequate resourcing of development programs, poor leadership, poor interdisciplinary relationships, role conflict, resistance to change, and poor teamwork, uneven population growth, shortage of human resources in trauma unit, the competent nurse staff with adequate years of experience is crucial in caring of patients with chest trauma, non-compliance among nurses are associated with insufficient knowledge, workload, forgetfulness, workplace safety. This study result is in agreement with Daly et al., (2014). Who said that developing clinical leadership skills among hospital nurses and other health professionals is of critical importance? According to Damkliang et al., (2015) the emergency nurses from the study evidence suggests that adequate support from nurse administrators or members of the healthcare team are a major facilitator to guideline use. Also, this is in agreement with José, et al., (2013).who mentioned that leadership in nursing, as well as being a complex social phenomenon, is a fundamental instrument for care management that requires nurses' commitment to the quest for continuous improvement of their skills and potential. For an effective exercise of leadership, it is important that the nurse be responsible, committed to the work of maintaining effective communication with the nursing team. In addition de Lima Gomes et al., (2016). Reported that paramount importance to the availability of human resources, and structural materials in quantity and quality to reduce the possibility of adverse events and contribute to the best multiple trauma patients Similarly, the agreement with a study done by Visser, (2017) who reported that lack of workplace resources, high workload, traumatic experiences, limited support from management and no access to psychological support services. These results agree with Vasli \& Dehghan-Nayeri, (2016) Who believed that an imbalance manifests itself in the form of unpredictability, crowding, and chaos, and can be 
caused by internal or external factors. They also emphasized the necessity of appropriate resources of equipment, facilities, and physical structure, as well as the application of managerial skills by the staff, especially head nurses, and financial-welfare, emotional, and legal, personnel who participated in their research claimed not to have received adequate support from hospital administrators during the majority of traumatic events. This study result is in agreement with Scurlock \& Becker, (2016). Who stated that the lack of financial resources, uneven population growth, and, most importantly, limited numbers of health care professionals to deal with these changes have forced the medical community to look at alternative methods to care for the critically ill.

Stated by Rn et al., (2017) Enhancing the selfefficacy of emergency nurses when performing assessment has the potential to improve their ability to carrying out urgent tasks and improve patient outcomes. Likewise, with the junior medical staff, the trauma staff who oversee monitoring of the protocol activation have committed to providing more realtime feedback and around nursing staff behavior. According to Staffileno, (2013) the quality outcomes with cost-effectiveness are the cornerstone of the direction of health care in the United States. Incorporating the $\mathrm{PhD}$ nurse researcher role inpatient care settings will affirmatively impact quality and short and long-term financial operational costs.

As well, the great majority in the current study had unsatisfactory Nurses Knowledge chest trauma Compliance Assessment. This is an expected finding. Due to lack of preparation during the basic education, lack of desire of nurses to acquire new knowledge, overload in the working situation and lack of continuing education courses related to the care of the patient with chest trauma. And all nurses with a diploma degree and Technical Institute of Nursing, Nurses with the not specific qualification about chest trauma. This result is congruent with (Yousef, Mohamed, Ali, \& Ali, 2018) In Egypt, nursing is a female occupation, and this gives a reason why the entire study sample was female . The unsatisfactory level of nurses knowledge in the initial assessment might be due to the inadequate educational preparation level and lack of in-service training, This result is congruent with (Carla, et al., 2018) A Brazilian study, with 146 nurses, emphasizes that nurses recognize that continuous education is an important tool that has a positive influence in the nursing care in a way that they could enhance their knowledge The present study agreement with (Rasouli, et al., 2016) Within limitation of his study the results show that majority of participants had low level of knowledge about trauma and taking care of traumatic patients in both male and female staff and in both the results of the study represented that there was no significant difference in their level of knowledge in regard to their demographic characteristics. According to the epidemiology of trauma, Also, these results are in agreement with (Hatata et al., 2018) \& (Hatata et al., 2013) The total knowledge score and the score of all its items increased significantly immediate post-intervention. This reflects the lack of knowledge among nursing about the chest trauma and falls. This study Agreement with (Curtis, Lien, Chan, Grove, \& Morris, 2002) their analysis of the impact of the trauma nurse practitioner on the quality of care for trauma patients in a large US institution found that the introduction of a trauma nurse practitioner reduced the time of surgical house-staff activities such as teaching patients and completing discharge. Also, this study agreement by(Goldstein et al., 2017) This may be due to nurses' lack of confidence in their ability to differentiate between mild, moderate and severe pain, the pain severity discriminator not actually changing the triage category, or, sadly, staff becoming immune to patients' complaints of pain (pain is one of the most common reasons for presentation to $\mathrm{t}$ Also, these results are in agreement with (Feizi Nazarloo et al., 2017) In the present study, most subjects had a poor awareness status, regarding the field of protection of forensic evidence. In a study conducted in emergency wards of the city of Durban, South Africa, most nurses had problems with the protection of forensic evidence and had not experienced any training in the protection chain, moreover, disagreement by (Elfaki et al., 2016) Nurses had good knowledge about indications and time for chest tube removal and average knowledge about the basic principles of chest derange system function, complications, action when trauma leakage and dislodge and had poor knowledge to do action when the traumas displacement.

\section{Conclusion}

Based on the results of the current study it can be concluded that the main factor affecting the compliance of the nurses staff regarding the care of patients chest trauma were: The following no clear job description, did not have any oriented program or continuous training courses, no written information such as (poster, brochure, equipped new book, Journal website), no facilities to update their knowledge and practical skill in chest trauma, Undergraduates courses did not cover the care of patients with chest trauma and Lack of financial resources in trauma unit. 


\section{Recommendations}

Based on the finding of the current study, the following

- Provide the nurses with a clear job description in service training program update their knowledge and practical skill nurses about the care of patients with chest trauma, and financial resources in the trauma unit for enhancing that quality of care.

- Encouraging the studied nurses caring of patients with a chest trauma to attend regular formal in-service educational programs about chest trauma.

- Nursing school curriculum must include all items about the care of patients with chest trauma care.

- Provide the studied nurses with the procedure book and the poster regarding nursing guideline for caring of patients with chest trauma .

- Studying the impact of educational programs on the reasons compliance regarding the care of patients with chest trauma continuously using a wide probability sample in different areas to monitor improvement in nurses' performance

- Study points of weakness for conducting educational program to nurses caring of patients with a chest trauma to improve nurse's performance including the financial resource.

- Booklets about the care of patients with chest trauma should be available in each department unit of the critical care unit and emergency in the hospital

\section{References}

1. Bedier, N., Bakr Abo EL-Ata, A., \& Mohammed I., (2016): international journal of nursing didactics Impact of an Educational Program on Nurses' Knowledge Related to Care of Patients with Chest Tube. International Journal of Nursing Didactics, 6.

2. Carla, A., Alexandre, S., Silva, J., Oliveira, W., \& Barros, J., De, (2018): Nursing Conduct for Major Trauma Patients : Initial Care Provided at the Red Nursing Conduct for Major Trauma Patients: Initial Care Provided at the Red Zone of an Emergency Department, (April).

3. Cattermole, G., Manirafasha, A., Aluisio, A., \& Mbanjumucyo, G., (2018): Freely Accessible Medical Education (FAME) for Africa. African Journal of Emergency Medicine, 8(2), 41-42.

4. Chipeta, E., Bradley, S., Chimwaza-Manda, W., \& McAuliffe, E., (2016): Working relationships between obstetric care staff and their managers: A critical incident analysis. BMC Health Services Research, 16(1), 1-9.

5. Chowdhry, T., \& Rathinam, S., (2017):
Penetrating injuries of the chest. Surgery (United Kingdom), 35(5), 255-261.

6. Chowdhury, T., Kowalski, S., Arabi, Y., \& Dash, H., (2014): Pre-hospital and initial management of head injury patients: An update. Saudi Journal of Anaesthesia, 8(1), 114.

7. Curtis, K., Caldwell, E., Delprado, A., \& Munroe, B., (2012): Traumatic injury in Australia and New Zealand. Australasian Emergency Nursing Journal, 15(1), 45-54.

8. Curtis, K., Lien, D., Chan, A., Grove, P., \& Morris, R., (2002): The impact of trauma case management on patient outcomes. The Journal of Trauma, 53(3), 477-482.

9. Lima G., Barreto T., Dos, S., De Lima F., (2016): Multiple Trauma patient Safety in Emergency Care:Scoping Review. International Archives of Medicine, 1-14

10. Diab, G., \& Mabrouk, S., (2015): The effect of guidance booklet on knowledge and attitudes of nurses regarding disaster preparedness at hospitals. Journal of Nursing Education and Practice, 5(9), 17-31.

11. Efstathiou, G., Papastavrou, E., Raftopoulos, V., \& Merkouris, A., (2011): Factors influencing nurses' compliance with Standard Precautions in order to avoid occupational exposure to microorganisms: A focus group study. BMC Nursing, 10(1), 1.

12. Elfaki, B., Mustafa, H., \& Hassan Ahmed, A., (2016): Nurses' knowledge and Practice regard Care of Patient with Chest Drains in Sudan Heart Center, Khartoum, Sudan. IOSR Journal of Nursing and Health Science, 5, 2320-1940.

13. Eskander, H., Morsy, W., \& Elfeky, H., (2013): Intensive Care Nurses ' Knowledge \& Practices regarding Infection Control Standard Precautions at a Selected Egyptian Cancer Hospital. Journal of Education and Practice, 4(19), 160-174.

14. Feizi Nazarloo, L., Sedghi Sabet, M., JaafarAghaii, F., Kazem Nezhad Leyli, E., Rahbar Taromsari, M., \& Jolly, A., (2017): Emergency Department Nurses's Knowledge about Forensic Nursing. Journal of Holistic Nursing And Midwifery, 27(3), 27-36.

15. Garvey, P., Liddil, J., Eley, S., \& Winfield, S., (2016): Trauma tactics: Rethinking Trauma education for professional nurses. Journal of Trauma Nursing, 23(4), 210-214.

16. Hassanin, A., \& Mohammed, H., (2016): Effect of an Educational program for nurse 's working at Mansoura University Hospitals on Chest Tube Complications . 5(5), 34-42.

17. Hatata, E., Soliman, S., Refaat, R., \& Professor, A., (2013): Prevention of recurrent 
falls in elderly: a pre-post intervention study in a rural community, Egypt. International Journal of Collaborative Research on Internal Medicine \& Public Health, 5(4), 187-198.

18. Hertel, R., (2011): Regulating Patient Staffing: A Complex Issue National Legislation to Regulate Nurse-Patient Staffing Ratios Support for Regulating Nurse-Patient Staffing Ratios. 21(1), 3-7.

19. Hussain, F., Khatoon, R., Sachan, B., \& Srivastava, J., (2018): Knowledge and practice of the universal precaution among nursing students of Eras's Lucknow Medical College and Hospital, Lucknow. International Journal Of Community Medicine And Public Health, 5(8), 3326.

20. Ibrahim, R., (2016a): Impact of an Educational Program on Knowledge and Practices of Nurses about Caring of Patient with Chest Tube. IOSR Journal of Nursing and Health Science, 5(6), 2320-1940.

21. Ibrahim, R., (2016b): Impact of an Educational Program on Knowledge and Practices of Nurses about Caring of Patient with Chest Tube. IOSR Journal of Nursing and Health Science, 5, 23201940.

22. José Luís, S., Lima Alice, M., Lima Pestana Aline, Regina Garlet Estela, \& Lorenzini Erdmann Alacoque, (2013): Challenges for the management of emergency care from the perspective of nurses. Acta Paulista de Enfermagem, 26(2),

23. Milisavljević, S., Spasić, M., Arsenijević, M., Sharp, C., Hons, B., Dacvecc, M., Access, O., (2016): The Poly-Traumatized Patient with Fractures. Journal of Trauma and Acute Care Surgery, $\quad 7(6), \quad 1-437$. https://doi.org/10.1007/978-3-662-47212-5

24. Mitra, B., Mathew, J., Gupta, A., Cameron, P., O'Reilly, G., Soni, K., Fitzgerald, M., (2017): Protocol for a prospective observational study to improve prehospital notification of injured patients presenting to trauma centres in India. BMJ Open, 7(7).

25. Rasouli, A., Alizadeh, S., Vahdati, S., Jafarabadi, M., \& Pouraghaei, M., (2016): Investigating nursing students' level of knowledge in caring for trauma patients. Acta Medica Mediterranea, 32(SpecialIssue2), 10621066.

26. Record of trauma emergency unit Assuit hospital2019

27. Scurlock, C., \& Becker, C., (2016): Telemedicine for Trauma and Emergency: the
eICU. Current Trauma Reports, 2(3), 132-137.

28. Spanjersberg, W., Bergs, E., Mushkudiani, N., Klimek, M., \& Schipper, I., (2009): Protocol compliance and time management in blunt trauma resuscitation. Emerg Med J, 26(1), 23-27.

29. Stewart, D., (2014): Blunt Chest Trauma. Journal of Trauma Nursing, 21(6), 282-284.

30. Sundaram, R., \& Parkinson, R., (2007): Universal precaution compliance by orthopaedic trauma team members in a major trauma resuscitation scenario. Annals of the Royal College of Surgeons of England, 89(3), 262-267.

31. Tevington, P., (2011): Mandatory nurse-patient ratios. Medsurg Nursing: Official Journal of the Academy of Medical-Surgical Nurses, 20(5), 265-268.

32. Yousef, A., Mohamed, W., Ali, F., \& Ali, E., (2018): Effect of Nursing Education Guidelines about High Alert Medications on Critical Care Nurses Knowledge and Practices ., 7(1), 47-54.

33. Vasli, P., \& Dehghan-Nayeri, N., (2016); Emergency nurses' experience of crisis: A qualitative study. Japan Journal of Nursing Science, 13(1), 55-64.

34. Vaz, K., McGrowder, D., Alexander-Lindo, R., Gordon, L., Brown, P., \& Irving, R., (2010): Knowledge, awareness and compliance with universal precautions among health care workers at the University Hospital of the West Indies, Jamaica. The International Journal of Occupational and Environmental Medicine, 1(4), 171-181.

35. Visser, B., \& M. (2017): Challenges in Nursing : The Psychological Needs of Rural. 2, 1-6. 